\title{
Análise de fatores e regressão bissegmentada em estudos de estratificação ambiental e adaptabilidade em milho
}

\author{
Deoclécio Domingos Garbuglio(1), Antonio Carlos Gerage(2), Pedro Mário de Araújo(2), \\ Nelson da Silva Fonseca Junior ${ }^{(2)}$ e Pedro Sentaro Shioga ${ }^{(3)}$
}

\begin{abstract}
(1)Escola Superior de Agricultura Luiz de Queiroz, Dep. de Genética, Av. Pádua Dias, no 11, Caixa Postal 9, CEP 13418-900 Piracicaba, SP. E-mail: deocleciodg@yahoo.com.br (2)Instituto Agronômico do Paraná (lapar), Área de Melhoramento e Genética Vegetal, Rod. Celso Garcia Cid, Km 375, Caixa Postal 481, CEP 86066-210 Londrina, PR. E-mail: milhoger@iapar.br, pmaraujo@iapar.br, nsfj@@iapar.br(3)Iapar, Área de Fitotecnia. E-mail: shioga@iapar.br
\end{abstract}

Resumo - O objetivo deste trabalho foi verificar possíveis divergências entre os resultados obtidos nas avaliações da adaptabilidade de 27 genótipos de milho (Zea mays L.), e na estratificação de 22 ambientes no Estado do Paraná, por meio de técnicas baseadas na análise de fatores e regressão bissegmentada. As estratificações ambientais foram feitas por meio do método tradicional e por análise de fatores, aliada ao porcentual da porção simples da interação GxA (PS\%). As análises de adaptabilidade foram realizadas por meio de regressão bissegmentada e análise de fatores. Pela análise de regressão bissegmentada, os genótipos estudados apresentaram alta performance produtiva; no entanto, não foi constatado o genótipo considerado como ideal. A adaptabilidade dos genótipos, analisada por meio de plotagens gráficas, apresentou respostas diferenciadas quando comparada à regressão bissegmentada. A análise de fatores mostrou-se eficiente nos processos de estratificação ambiental e adaptabilidade dos genótipos de milho.

Termos para indexação: Zea mays, interação genótipo x ambiente, estabilidade.

\section{Factor analysis and bissegmented regression for studies about environmental stratification and maize adaptability}

\begin{abstract}
The objective of this work was to verify possible divergences among results obtained on adaptability evaluations of 27 maize genotypes (Zea mays L.), and on stratification of 22 environments on Paraná State, Brazil, through techniques of factor analysis and bissegmented regression. The environmental stratifications were made through the traditional methodology and by factor analysis, allied to the percentage of the simple portion of GxE interaction (PS\%). Adaptability analyses were carried out through bissegmented regression and factor analysis. By the analysis of bissegmented regression, studied genotypes had presented high productive performance; however, it was not evidenced the genotype considered as ideal. The adaptability of the genotypes, analyzed through graphs, presented different answers when compared to bissegmented regression. Factor analysis was efficient in the processes of environment stratification and adaptability of maize genotypes.
\end{abstract}

Index terms: Zea mays, genotype x environment interaction, stability.

\section{Introdução}

Nos programas de melhoramento genético das diversas espécies, inclusive o milho (Zea mays L.), a interação genótipo x ambiente (GxA) dificulta a seleção e indicação de cultivares, em razão da inconsistência de performance dos genótipos em ambientes distintos.

A interação GxA pode ser dividida em duas partes. Uma de natureza simples, quando não ocorre alteração das posições relativas dos genótipos avaliados, dentro de um conjunto de ambientes, tomados dois a dois. A outra, chamada de complexa, ocorre quando a correlação entre o desempenho dos genótipos ao longo dos ambientes em estudo é baixa, o que faz com que a posição relativa dos genótipos seja alterada em virtude das diferentes respostas às variações ambientais (Robertson, 1959).

Para que as indicações de genótipos sejam mais seguras, devem ser tomadas medidas que busquem controlar ou amenizar os efeitos da interação GxA 
(Cruz \& Carneiro, 2003). No sentido biométrico, duas abordagens são empregadas: a dos estudos de estabilidade e adaptabilidade de diferentes genótipos em que, segundo Cruz et al. (2004), procura-se particularizar as respostas de cada genótipo diante das variações ambientais, para identificar aqueles de adaptabilidade ampla ou específica e, ainda, os de comportamento previsível; e a relativa aos métodos de estratificação ambiental, por meio da análise da interação GxA.

Nas análises de estabilidade e adaptabilidade, modelos fundamentados no método de regressão bissegmentada vêm sendo amplamente utilizados. O método contempla a formação de grupos de ambientes favoráveis, onde os índices ambientais apresentam valores positivos, e de ambientes desfavoráveis, onde os índices são negativos (Cruz et al., 2004). Questionamentos vêm sendo feitos quanto à possibilidade de se detectar com precisão se um genótipo apresenta diferença de comportamento em ambientes inferiores ou superiores.

O processo de estratificação ambiental consiste na subdivisão de regiões heterogêneas em sub-regiões mais uniformes, onde se exclui qualquer interação GxA significativa ou, em outras situações, uma interação significativa com predominância de porção simples, ou seja, que não venha a comprometer a recomendação das cultivares. Busca-se, assim, reunir ambientes de classificação genotípica similar, independentemente da qualidade ambiental. No entanto, este método apresenta consistência somente para interação de genótipos x locais e não para genótipos x anos, genótipos x safras ou genótipos $\mathrm{x}$ locais $\mathrm{x}$ anos (Oliveira et al., 2005).

A análise de fatores é uma técnica multivariada utilizada, entre outras formas, nos estudos de estratificação ambiental, que permite reduzir um número elevado de variáveis originais a um pequeno número de variáveis abstratas, também chamadas de fatores (Cruz \& Carneiro, 2003). Cada fator irá agrupar um conjunto de ambientes, altamente correlacionados entre si e fracamente correlacionados com os ambientes, agrupados nos demais fatores.

Os estudos de adaptabilidade, estabilidade e de estratificação ambiental vêm sendo realizados de forma dissociada. Murakami \& Cruz (2004) propuseram um método que contempla, simultaneamente, a análise de adaptabilidade e de estratificação ambiental, por meio do princípio da similaridade da performance fenotípica, baseada na técnica de análise de fatores.

Este trabalho teve por objetivo verificar possíveis divergências entre os resultados obtidos nas avaliações da adaptabilidade de 27 genótipos de milho (Zea mays), e na estratificação de 22 ambientes no Estado do Paraná, por meio de técnicas baseadas na análise de fatores e regressão bissegmentada.

\section{Material e Métodos}

Foram coletados na Rede Estadual de Avaliação de Cultivares de Milho, coordenada pelo Instituto Agronômico do Paraná, dados de 27 cultivares comerciais de milho de ciclo precoce, em 11 localidades no Estado do Paraná (Londrina, Cambará, Campo Mourão, Goioerê, Palotina, Cascavel, Pato Branco, Francisco Beltrão, Guarapuava, Ponta Grossa e Wenceslau Bráz), em dois anos agrícolas (2003/2004 e 2004/2005), num total de 22 ambientes.

Os ensaios foram realizados em delineamento de blocos ao acaso com três repetições. A área útil de cada parcela foi constituída de duas linhas de $5 \mathrm{~m}$, com $80 \mathrm{~cm}$ entre linhas, $20 \mathrm{~cm}$ entre plantas, tendo-se obtido 25 plantas por linha após desbaste. Os controles de pragas e plantas daninhas foram realizados quando necessário. Os dados utilizados nas análises referemse ao peso de grãos por parcela, corrigido para 14,5\% de umidade e ajustado para quilograma por hectare.

Inicialmente, foram realizadas as análises de variância individuais e, depois de verificadas as magnitudes dos quadrados médios residuais, foi realizada a análise conjunta. Os efeitos de locais e anos de avaliação foram considerados como aleatórios, e o efeito de genótipos como fixos.

Os parâmetros de adaptabilidade $\left(\beta_{0}, \beta_{1}, \beta_{1}+\beta_{2}\right)$ e estabilidade $\left(\hat{\sigma}_{\delta \mathrm{i}}^{2}, \mathrm{R}^{2}\right)$ foram estimados por meio de análise de regressão bissegmentada pelo método de Cruz et al. (1989). O modelo adotado foi: $Y_{i j}=b_{0 i}+$ $b_{\mathrm{li}} \mathrm{I}_{\mathrm{j}}+\mathrm{b}_{2 \mathrm{i}} \mathrm{T}\left(\mathrm{I}_{\mathrm{j}}\right)+\sigma_{\mathrm{ij}}+\mathrm{e}_{\mathrm{ij}}$, em que: $\mathrm{Y}_{\mathrm{ij}}$ é a média da cultivar i no ambiente $\mathrm{j} ; \mathrm{I}_{\mathrm{j}}$ é o índice ambiental; $\mathrm{T}\left(\mathrm{I}_{\mathrm{j}}\right)=0$ se $\mathrm{I}_{\mathrm{j}}<0$; $\mathrm{T}\left(\mathrm{I}_{\mathrm{j}}\right)=\mathrm{I}_{\mathrm{j}}-\mathrm{I}_{+}$se $\mathrm{I}_{\mathrm{j}}>0$, em que $\mathrm{I}_{+}$é a média dos índices $\mathrm{I}_{\mathrm{j}}$ positivos; $b_{0 \mathrm{i}}$ é a média geral da cultivar $\mathrm{i} ; \mathrm{b}_{1 \mathrm{i}}$ é o coeficiente de regressão linear associado a $\mathrm{I}_{\mathrm{j}} ; \mathrm{b}_{2 \mathrm{j}}$ é o coeficiente de regressão linear associado a $\mathrm{T}\left(\mathrm{I}_{\mathrm{j}}\right) ; \sigma_{\mathrm{ij}}$ é o desvio da regressão linear; $e_{i j}$ é o erro-médio experimental.

As análises de estratificação ambiental foram realizadas pelo método tradicional proposto por Lin (1982), e análise de fatores proposta por Murakami \& Cruz (2004). Foi estimada também a fração simples da interação GxA, de acordo com o método de Cruz \& Castoldi (1991).

O número de fatores finais considerados na estratificação ambiental, por meio de análise de fatores, 
pode ser igual ao número de autovalores iguais ou superiores a 1 (Cruz \& Carneiro, 2003). Porém, podem ocorrer situações em que a proporção da variação explicada pelo autovalores maiores que 1 seja baixa. Assim, devem-se considerar mais fatores até que se atinja, pelo menos, $80 \%$ da variabilidade total.

O agrupamento dos ambientes foi considerado a partir de cargas fatoriais finais maiores que 0,70 , obtidas após rotação, o que indica que esses ambientes apresentam alta correlação e podem ser agrupados em um mesmo fator. Cargas fatoriais de valores iguais ou abaixo de 0,50 indicam que o ambiente em questão não deva pertencer ao grupo. Para cargas fatoriais com valores entre 0,50 e 0,70 não há garantia de definição para o agrupamento. A extração das cargas fatoriais foi feita pelo método dos componentes principais, e os fatores estabelecidos pelo método de rotação varimax, com um máximo de 50 rotações. As análises foram realizadas com auxílio dos programas Genes (Cruz, 2005) e SAS (SAS Institute, 1999).

A análise de adaptabilidade fenotípica, baseada na técnica de análise de fatores, foi realizada graficamente por meio de escores obtidos em relação aos fatores. De acordo com Murakami \& Cruz (2004), nos quadrantes II e IV, estarão os genótipos com adaptabilidade específica aos ambientes, agrupados em cada um dos dois fatores utilizados na plotagem gráfica. No quadrante I, estarão os genótipos de adaptabilida- de ampla, ou seja, apresentarão escores altos para os ambientes agrupados nos dois fatores, simultaneamente. No quadrante III, estarão os genótipos de baixa performance, passíveis de não indicação de cultivo para os ambientes em estudo.

\section{Resultados e Discussão}

Foi verificado, por meio das análises de variâncias individuais (Tabela 1) que, em razão da alta significância $(\mathrm{p}<0,01)$ pelo teste $\mathrm{F}$, os genótipos tiveram comportamento distinto dentro de cada ambiente em estudo. Os $\mathrm{CV}_{\mathrm{e}}$ oscilaram entre 3,94\% (ambiente 12) e 13,29\% (ambiente 19), com média de 6,71\%, o que indica alta precisão experimental do conjunto de ensaios. As médias de produtividade ficaram entre $6.713 \mathrm{~kg} \mathrm{ha}^{-1}$ (ambiente 6) e $12.228 \mathrm{~kg} \mathrm{ha}^{-1}$ (ambiente 18), com média geral de $9.816 \mathrm{~kg} \mathrm{ha}^{-1}$. A partir dos índices ambientais $\left(\mathrm{I}_{\mathrm{j}}\right), 13$ ambientes foram classificados como favoráveis, enquanto nove foram classificados como desfavoráveis.

Verificou-se que a razão entre o maior e o menor valor para os quadrados médios do erro, foi de 4,2. Segundo Banzatto \& Kronka (1995), uma razão menor que sete indica que há homogeneidade das variâncias residuais obtidas nas análises, o que possibilita a realização da análise conjunta dos locais, sem restrições.

Tabela 1. Ambientes e anos de avaliação, qualidade de acordo com índices ambientais $\left(\mathrm{I}_{\mathrm{j}}\right)$, quadrados médios dos tratamentos e do erro das análises de variância individuais, produtividade média dos ensaios, coeficiente de variação ambiental $\left(\mathrm{CV}_{\mathrm{e}}\right)$.

\begin{tabular}{|c|c|c|c|c|c|c|}
\hline \multirow[t]{2}{*}{ Ambientes } & \multirow[t]{2}{*}{ Ano } & \multirow[t]{2}{*}{$\mathrm{I}_{\mathrm{j}}^{(1)}$} & \multicolumn{2}{|c|}{ Quadrado médio } & \multirow{2}{*}{$\begin{array}{c}\text { Produtividade média } \\
\left(\mathrm{kg} \mathrm{ha}^{-1}\right)\end{array}$} & \multirow{2}{*}{$\begin{array}{l}\mathrm{CV}_{\mathrm{e}} \\
(\%)\end{array}$} \\
\hline & & & Tratamentos $\left(\mathrm{x} 10^{5}\right)$ & Erro $\left(\times 10^{4}\right)$ & & \\
\hline 1.Londrina & $2004 / 2005$ & $\mathrm{~F}$ & $25,83 * *$ & 25,28 & 10.163 & 4,95 \\
\hline 2. Cambará & $2004 / 2005$ & $\mathrm{D}$ & $37,27 * *$ & 36,18 & 9.280 & 6,48 \\
\hline 3. Campo Mourão & $2004 / 2005$ & $\mathrm{~F}$ & $60,80 * *$ & 40,41 & 10.508 & 6,05 \\
\hline 4. Goioerê & $2004 / 2005$ & $\mathrm{D}$ & $21,35 * *$ & 37,26 & 7.611 & 8,02 \\
\hline 5. Palotina & $2004 / 2005$ & $\mathrm{~F}$ & $30,10 * *$ & 43,15 & 10.298 & 6,38 \\
\hline 6. Cascavel & $2004 / 2005$ & $\mathrm{D}$ & $27,18 * *$ & 41,11 & 6.713 & 9,55 \\
\hline 7. Pato Branco & $2004 / 2005$ & $\mathrm{~F}$ & $28,47 * *$ & 43,16 & 10.880 & 6,04 \\
\hline 8. Francisco Beltrão & $2004 / 2005$ & $\mathrm{~F}$ & $38,31 * *$ & 61,50 & 10.614 & 7,39 \\
\hline 9. Guarapuava & $2004 / 2005$ & $\mathrm{D}$ & $25,26 * *$ & 31,43 & 9.292 & 6,03 \\
\hline 10. Ponta Grossa & $2004 / 2005$ & $\mathrm{D}$ & $31,98 * *$ & 31,49 & 9.371 & 5,99 \\
\hline 11. Wenceslau Bráz & $2004 / 2005$ & $\mathrm{D}$ & $54,15 * *$ & 30,16 & 9.294 & 5,91 \\
\hline 12. Londrina & $2003 / 2004$ & $\mathrm{~F}$ & $28,09 * *$ & 22,65 & 12.095 & 3,94 \\
\hline 13. Cambará & $2003 / 2004$ & $\mathrm{D}$ & $23,45 * *$ & 38,63 & 9.179 & 6,77 \\
\hline 14. Campo Mourão & $2003 / 2004$ & $\mathrm{~F}$ & $40,99 * *$ & 37,19 & 10.008 & 6,09 \\
\hline 15. Goioerê & $2003 / 2004$ & $\mathrm{~F}$ & $17,46^{* *}$ & 34,46 & 10.283 & 5,71 \\
\hline 16. Palotina & $2003 / 2004$ & $\mathrm{~F}$ & $24,25 * *$ & 44,17 & 10.682 & 6,22 \\
\hline 17. Cascavel & $2003 / 2004$ & $\mathrm{~F}$ & $31,38 * *$ & 68,58 & 10.332 & 8,01 \\
\hline 18. Pato Branco & $2003 / 2004$ & $\mathrm{~F}$ & $30,99 * *$ & 68,15 & 12.228 & 6,75 \\
\hline 19. Francisco Beltrão & $2003 / 2004$ & $\mathrm{D}$ & $19,07 * *$ & 95,18 & 7.342 & 13,29 \\
\hline 20. Guarapuava & $2003 / 2004$ & $\mathrm{~F}$ & $32,58 * *$ & 63,11 & 10.407 & 7,63 \\
\hline 21. Ponta Grossa & $2003 / 2004$ & $\mathrm{~F}$ & $40,16^{* *}$ & 23,93 & 10.363 & 4,72 \\
\hline 22. Wenceslau Bráz & $2003 / 2004$ & $\mathrm{D}$ & $36,07 * *$ & 35,95 & 9.018 & 6,65 \\
\hline Média & & & & & 9.816 & 6,71 \\
\hline
\end{tabular}

${ }^{(1)} \mathrm{F}$ : ambiente favorável; D: ambiente desfavorável. **Significativo a $1 \%$ de probabilidade pelo teste $\mathrm{F}$. 
A partir da análise conjunta (Tabela 2), foi constatado que a fonte de variação Genótipos foi significativa a $1 \%$ de probabilidade no conjunto dos 22 ambientes. Essa alta significância foi verificada, também, para ambientes, de onde se infere que o conjunto foi composto por ambientes distintos. Para a variável GxA, foi verificada alta significância $(p<0,01)$, o que indica que os genótipos apresentaram respostas diferenciadas em cada ambiente de avaliação.

Tabela 2. Análise de variância conjunta para rendimento de grãos $\left(\mathrm{kg} \mathrm{ha}^{-1}\right)$ de 27 genótipos de milho, em 22 ambientes no Estado do Paraná, nas safras 2003/2004 e 2004/2005.

\begin{tabular}{lrc}
\hline Fonte de variação & GL & $\begin{array}{c}\text { Quadrado médio } \\
\text { dos tratamentos }\left(\times 10^{5}\right)\end{array}$ \\
\hline Blocos/ambientes & 42 & 15,9 \\
Genótipos (G) & 26 & $353,1^{* *}$ \\
Ambientes (A) & 21 & $1.474,2^{* *}$ \\
GxA & 546 & $16,8^{* *}$ \\
Erro experimental médio & 1.144 & 4,3 \\
\hline
\end{tabular}

**Significativo a $1 \%$ de probabilidade pelo teste $\mathrm{F}$.
Cruz et al. (2004) classificaram como genótipo ideal aquele que apresenta alta produtividade $\left(\beta_{0}\right)$, seja pouco responsivo em ambientes desfavoráveis $\left(\beta_{1}<1\right)$, e responsivo em ambientes favoráveis $\left(\beta_{1}+\beta_{2}>1\right)$. No conjunto de materiais estudados, tal genótipo não foi identificado (Tabela 3). Uma crítica que se pode fazer a esse método diz respeito à exigência do genótipo em ser pouco responsivo em ambientes desfavoráveis. Em termos numéricos, este cuidado é para prevenir que a reta da equação de regressão não atinja pontos inferiores em ambientes mais pobres, se ela tiver uma inclinação de $\beta_{1} \geq 1$. Mas se $\beta_{0}$ está entre as mais elevadas, o genótipo é valioso e, nesse caso, o método pouco contribui para entender a falta de resposta à melhoria dos ambientes favoráveis, bem como a magnitude e a significância dos desvios da regressão que causam receio quanto à estabilidade de produção.

Por meio dos parâmetros obtidos pelo método de Cruz et al. (1989), os genótipos DOW 766 e TRACTOR mostraram-se pouco responsivos nos ambientes desfavo-

Tabela 3. Estimativas dos parâmetros de adaptabilidade e estabilidade de 27 genótipos de milho, em 22 ambientes no Estado do Paraná, nas safras 2003/2004 e 2004/2005, segundo o método de Cruz et al. (1989).

\begin{tabular}{|c|c|c|c|c|c|c|c|}
\hline Cultivares & $\beta_{0}^{(1)}$ & $\begin{array}{c}\mathrm{D}^{(2)} \\
\left(\mathrm{kg} \mathrm{ha}^{-1}\right.\end{array}$ & $\mathrm{F}^{(3)}$ & $\beta_{1}$ & $\beta_{1}+\beta_{2}$ & $\hat{\sigma}_{\delta \mathrm{i}}^{2^{(4)}}$ & $\mathrm{R}^{2}$ \\
\hline 1. AG 6018 & 10.015 & 8.848 & 10.822 & 0,92 & 1,01 & $127,3 * *$ & 87 \\
\hline 2. AG 8021 & 11.068 & 9.675 & 12.032 & 1,07 & 1,20 & $210,9 * *$ & 87 \\
\hline 3. AG 9020 & 10.214 & 8.780 & 11.207 & 1,12 & 1,07 & $398,5 * *$ & 82 \\
\hline 4. BALU 551 & 9.743 & 8.544 & 10.572 & 1,03 & 0,93 & $473,6 * *$ & 77 \\
\hline 5. BALU 761 & 10.136 & 8.708 & 11.124 & 1,08 & 1,13 & $56,1^{\mathrm{ns}}$ & 92 \\
\hline 6. BRS 1010 & 9.250 & 7.817 & 10.242 & 1,03 & 1,26 & $580,0 * *$ & 76 \\
\hline 7. BRS 2020 & 9.120 & 7.891 & 9.972 & 0,92 & 1,11 & $40,2^{\mathrm{ns}}$ & 91 \\
\hline 8. CD 305 & 8.181 & 6.839 & 9.109 & 0,90 & 0,84 & $265,0 * *$ & 80 \\
\hline 9. CD 306 & 9.259 & 8.158 & 10.022 & 0,94 & 1,27 & $205,6 * *$ & 85 \\
\hline 10. CD 307 & 9.907 & 8.584 & 10.822 & 1,00 & 1,06 & $309,9 * *$ & 82 \\
\hline 11. DOW 766 & 9.637 & 8.710 & 10.279 & $0,74^{(5)}$ & 0,97 & $152,1 * *$ & 81 \\
\hline 12. DOW 8460 & 9.588 & 8.195 & 10.552 & 1,09 & $1,37^{(5)}$ & $91,2 *$ & 92 \\
\hline 13. DG 501 & 9.476 & 8.087 & 10.438 & $1,16^{(5)}$ & $1,49^{(5)}$ & $231,4 * *$ & 89 \\
\hline 14. DKB 214 & 9.617 & 8.400 & 10.460 & 1,11 & $1,42^{(5)}$ & $784,4 * *$ & 75 \\
\hline 15. DKB 215 & 9.485 & 8.120 & 10.430 & $1,13^{(5)}$ & 1,17 & $984,3 * *$ & 70 \\
\hline 16. DKB 390 & 10.151 & 9.247 & 10.777 & $0,74^{(5)}$ & $0,11^{(5)}$ & $983,8 * *$ & 45 \\
\hline 17. DKB 747 & 10.084 & 8.577 & 11.127 & 1,10 & 1,05 & $1062,5 * *$ & 67 \\
\hline 18. DOW 8480 & 9.558 & 8.473 & 10.309 & 0,90 & 0,85 & $325,2 * *$ & 77 \\
\hline 19. P30F33 & 10.580 & 9.243 & 11.505 & $1,14^{(5)}$ & 0,99 & $144,0 * *$ & 90 \\
\hline 20. P30F90 & 11.203 & 9.979 & 12.050 & 1,11 & $0,66^{(5)}$ & $870,9 * *$ & 69 \\
\hline 21. P30F98 & 11.127 & 9.868 & 12.000 & 0,95 & 0,71 & $256,7 * *$ & 81 \\
\hline 22. PENTA & 10.543 & 9.391 & 11.341 & 0,96 & 1,00 & $57,0^{\mathrm{ns}}$ & 90 \\
\hline 23. PREMIUM & 10.459 & 9.117 & 11.389 & 1,06 & 0,84 & $650,5^{* *}$ & 73 \\
\hline 24. TORK & 9.826 & 8.733 & 10.583 & 1,02 & 0,93 & $394,6 * *$ & 79 \\
\hline 25. TRACTOR & 8.743 & 7.742 & 9.436 & $0,80^{(5)}$ & 0,77 & $20,1^{\mathrm{ns}}$ & 89 \\
\hline 26. XB 7011 & 9.264 & 7.864 & 10.233 & 1,04 & 1,03 & $427,4 * *$ & 79 \\
\hline 27. XB 7012 & 8.807 & 7.710 & 9.567 & 0,93 & 0,77 & $838,4 * *$ & 63 \\
\hline Médias & 9.816 & 8.567 & 10.682 & & & & \\
\hline
\end{tabular}

${ }^{(1)} \beta_{0}$ : média geral. ${ }^{(2)} \mathrm{D}$ : média nos ambientes desfavoráveis. ${ }^{(3)} \mathrm{F}$ : média nos ambientes favoráveis. ${ }^{(4)} \hat{\sigma}_{\delta \mathrm{i}}^{2} \mathrm{x} 10^{3}$. ${ }^{(5)} \mathrm{Difere}$ de 1 pelo teste $\mathrm{t}$, a $5 \%$ de

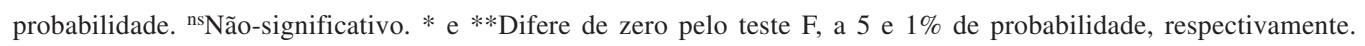


ráveis $\left(\beta_{1}<1\right)$ e com adaptabilidade ampla a ambientes favoráveis $\left(\beta_{1}+\beta_{2}=1\right)$. DOW 766 ainda apresentou variância dos desvios de regressão $\left(\hat{\sigma}_{\delta \mathrm{i}}^{2}\right)$ maior que zero, isto indica baixa estabilidade, o que não ocorreu com TRACTOR. Ainda, estes genótipos apresentaram produtividade média abaixo da média geral (DOW 766, $9.637 \mathrm{~kg} \mathrm{ha}^{-1}$; TRACTOR, $8.743 \mathrm{~kg} \mathrm{ha}^{-1}$ ). Os valores de $\mathrm{R}^{2}$ ficaram acima de $80 \%$ em ambos (DOW 766, 81\%; TRACTOR, $89 \%$ ), o que leva a inferir que $\hat{\sigma}_{\delta \mathrm{i}}^{2}$ não deve ser o único fator a atuar em uma provável recomendação das cultivares, e que a média de produtividade, ao longo dos ambientes, deverá ser levada em consideração.

DOW 8460 e DKB 214 apresentaram responsividade média nos ambientes desfavoráveis $\left(\beta_{1}=1\right)$ e foram altamente responsivos nos ambientes favoráveis $\left(\beta_{1}+\beta_{2}>1\right)$. Ambos se mostraram pouco estáveis $\left(\hat{\sigma}_{\delta \mathrm{i}}^{2}>0\right.$ ), porém DOW 8460 obteve $\mathrm{R}^{2}$ de $92 \%$, ao passo que DKB 214 apresentou coeficiente de determinação de 75\%. Os genótipos DKB 215 e P30F33 apresentaram baixa estabilidade $\left(\hat{\sigma}_{\delta \mathrm{i}}^{2}>0\right)$, foram altamente responsivos nos ambientes desfavoráveis $\left(\beta_{1}>1\right)$ e tiveram adaptabilidade ampla nos ambientes favoráveis $\left(\beta_{1}+\beta_{2}=1\right)$. DKB 215 obteve $\mathrm{R}^{2}$ de $70 \%$, enquanto P30F33 apresentou coeficiente de $90 \%$, além de um $\beta_{0}$ acima da média geral dos ensaios $\left(10.580 \mathrm{~kg} \mathrm{ha}^{-1}\right)$.

DG 501 se mostrou altamente responsivo tanto em ambientes desfavoráveis $\left(b_{1}>1\right)$ quanto em ambientes favoráveis $\left(\beta_{1}+\beta_{2}>1\right)$. Apresentou coeficiente de determinação de $89 \%$, porém com baixa estabilidade $\left(\hat{\sigma}_{\delta \mathrm{i}}^{2}>0\right)$, e produtividade abaixo da média geral $\left(9.746 \mathrm{~kg} \mathrm{ha}^{-1}\right)$, em ambientes desfavoráveis e favoráveis $(8.087$ e $10.438 \mathrm{~kg} \mathrm{ha}^{-1}$, respectivamente). P30F90, apesar da responsividade média nos ambientes desfavoráveis $\left(\beta_{1}=1\right)$, se mostrou pouco responsivo nos ambientes favoráveis $\left(\beta_{1}+\beta_{2}<1\right)$, baixa estabilidade $\left(\hat{\sigma}_{\delta i}^{2}>0\right)$ e um $R^{2}$ de $69 \%$. Apresentou, porém, um alto valor de $\beta_{0}$ (11.203 $\mathrm{kg} \mathrm{ha}^{-1}$ ), assim como alta produtividade nos ambientes desfavoráveis e favoráveis $\left(9.979\right.$ e $12.050 \mathrm{~kg} \mathrm{ha}^{-1}$, respectivamente).

Pelo método de Cruz et al. (1989), o genótipo menos adaptado, e altamente instável, foi DKB 390 com parâmetros $\beta_{1}<1, \beta_{1}+\beta_{2}<1, \hat{\sigma}_{\delta i}^{2}>0$ e coeficiente de determinação de $45 \%$. No entanto, apresentou produtividade acima da média geral $\left(\beta_{0}=10.151 \mathrm{~kg} \mathrm{ha}^{-1}\right)$, e da média nos ambientes desfavoráveis $\left(9.247 \mathrm{~kg} \mathrm{ha}^{-1}\right) \mathrm{e}$ favoráveis $\left(10.777 \mathrm{~kg} \mathrm{ha}^{-1}\right)$. Com base nos parâmetros de adaptabilidade obtidos e na performance produtiva, segundo Cruz et al. (2004), sua recomendação se restringiria aos ambientes desfavoráveis. Porém, uma recomendação fundamentada somente nos parâmetros estimados pelo modelo poderia excluir um material que tivesse baixa estabilidade, compreendida dentro de uma faixa de elevada produtividade, como no caso do genótipo DKB 390. Além das condições edafoclimáticas da região em questão, o nível tecnológico empregado pelo agricultor é de fundamental importância na cultura do milho, quanto à escolha do genótipo a ser cultivado.

Os genótipos BALU 761, BRS 2020 e PENTA, além de altos valores de $\mathrm{R}^{2}(92 \%, 91 \%$ e $90 \%$, respectivamente), mostraram-se muito estáveis $\left(\hat{\sigma}_{\delta \mathrm{i}}^{2}=0\right)$, com ampla adaptabilidade em ambientes favoráveis e desfavoráveis, e atingiram produtividade acima da média geral dos ensaios, com exceção de BRS 2020 (9.120 $\left.\mathrm{kg} \mathrm{ha}^{-1}\right)$.

Os demais genótipos apresentaram adaptabilidade ampla em ambientes favoráveis e desfavoráveis $\left(\beta_{1}\right.$ e $\left.\beta_{1}+\beta_{2}=1\right)$ e foram pouco estáveis $\left(\hat{\sigma}_{\delta \mathrm{i}}^{2}>0\right)$. Os coeficientes de determinação oscilaram entre $63 \%$ (XB 7012) e 87\% (AG 6018 e AG 8021). A produtividade média ficou em um intervalo entre $8.181 \mathrm{~kg} \mathrm{ha}^{-1}$ e $11.127 \mathrm{~kg} \mathrm{ha}^{-1}$ (CD 305 e P30F98).

Nas análises de estratificação ambiental, pelo método tradicional, baseado no algoritmo de Lin (1982), foi verificada a distribuição dos ambientes em seis grupos (Tabela 4). O grupo A foi composto pelos ambientes 1, 2 e 7 (Londrina, Cambará e Pato Branco, respectivamente - 2004/2005). O ambiente 1 também compôs o grupo B, com o ambiente 4 (Goioerê - 2004/2005). O grupo $\mathrm{C}$ foi composto pelos ambientes 7 (Pato Branco - 2004/2005) e 8 (Francisco Beltrão 2004/2005). Nota-se que os ambientes dos três primeiros grupos são da safra 2004/2005, no entanto, não houve formação de grupos com os demais ambientes da mesma safra (Campo Mourão, Palotina, Cascavel, Guarapuava, Ponta Grossa e Wenceslau Bráz). O mesmo fato ocorreu com os três grupos seguintes (D, E e F), compostos somente pelos ambientes 12, 13, 15, 21 e 22 (Londrina, Cambará, Goioerê, Ponta Grossa e Wenceslau Bráz - 2003/2004, respectivamente). $\mathrm{O}$ índice ambiental não foi fator preponderante no agrupamento, visto que os grupos A, C, E e F apresentaram

Tabela 4. Agrupamento dos 22 ambientes, segundo o método proposto por Lin (1982).

\begin{tabular}{ccccc}
\hline Grupo & Ambientes & $\begin{array}{c}\text { Quadrado médio } \\
\text { do erro }\left(\times 10^{4}\right)\end{array}$ & $\begin{array}{c}\text { Calculado } \\
\text { Tayy }\end{array}$ & Tabelado (5\%) \\
\hline A & 1,7 e 2 & 19,29 & 1,34 & 1,3 \\
B & 1 e 4 & 19,68 & 1,36 & 1,5 \\
C & 7 e 8 & 19,81 & 1,37 & 1,5 \\
D & 12 e 15 & 20,04 & 1,39 & 1,5 \\
E & 13 e 15 & 20,49 & 1,42 & 1,5 \\
F & 21 e 22 & 21,65 & 1,50 & 1,5 \\
\hline
\end{tabular}


tanto ambientes favoráveis quanto desfavoráveis nas suas composições.

A alta influência da porção complexa da interação GxA impediu que os demais ambientes viessem a compor os grupos formados, ou mesmo originar novos grupos. O índice ambiental é calculado pela diferença entre a média de um determinado ambiente em relação à média de todos os ambientes. A posição relativa dos materiais, ao longo dos ambientes em estudo é reflexo direto da interação simples ou complexa, assim, um ambiente é importante quando se propicia a falta de correlação, desde que seja representativo de uma con- dição ambiental expressiva, e sua ausência poderia implicar em dificuldades de posicionamento dos ambientes no mercado.

Cruz \& Castoldi (1991) definiram um método para formação de subgrupos com pares de ambientes, onde a interação GxA apresente natureza predominantemente simples, de modo que os genótipos apresentem comportamento coerente de um ambiente para outro ou que não sofram alterações relevantes que comprometam as recomendações das cultivares.

Das 231 combinações possíveis, entre os 22 ambientes de estudo (Tabela 5), apenas 23 combinações

Tabela 5. Porcentagem de parte simples da interação genótipo $\mathrm{x}$ ambiente e estimativas de correlações entre ambientes (r).

\begin{tabular}{|c|c|c|c|c|c|c|c|c|c|c|c|c|c|c|}
\hline Pares & PS (\%) & $\mathrm{r}$ & Pares & PS (\%) & $\mathrm{r}$ & Pares & PS (\%) & $\mathrm{r}$ & Pares & PS (\%) & $\mathrm{r}$ & Pares & PS (\%) & $\mathrm{r}$ \\
\hline $1 \times 2$ & 62,9 & 0,83 & $3 \times 9$ & 36,9 & 0,45 & $5 \times 20$ & 13,5 & 0,25 & $8 \times 21$ & 37,6 & 0,61 & $12 \times 21$ & 20,8 & 0,34 \\
\hline $1 \times 3$ & 72,8 & 0,83 & $3 \times 10$ & 38,0 & 0,53 & $5 \times 21$ & 8,5 & 0,14 & $8 \times 22$ & 37,5 & 0,61 & $12 \times 22$ & 26,9 & 0,45 \\
\hline $1 \times 4$ & 51,2 & 0,75 & $3 \times 11$ & 47,3 & 0,72 & $5 \times 22$ & 12,2 & 0,22 & $9 \times 10$ & 43,3 & 0,66 & $13 \times 14$ & 36,7 & 0,53 \\
\hline $1 \times 5$ & 42,0 & 0,66 & $3 \times 12$ & 24,6 & 0,30 & $6 \times 7$ & 29,7 & 0,51 & $9 \times 11$ & 26,8 & 0,34 & $13 \times 15$ & 47,8 & 0,71 \\
\hline $1 \times 6$ & 47,5 & 0,72 & $3 \times 13$ & 25,7 & 0,26 & $6 \times 8$ & 37,0 & 0,58 & $9 \times 12$ & 18,5 & 0,33 & $13 \times 16$ & 31,4 & 0,53 \\
\hline $1 \times 7$ & 58,4 & 0,82 & $3 \times 14$ & 21,7 & 0,35 & $6 \times 9$ & 15,0 & 0,28 & $9 \times 13$ & 22,4 & 0,40 & $13 \times 17$ & 38,8 & 0,61 \\
\hline $1 \times 8$ & 53,7 & 0,75 & $3 \times 15$ & 31,4 & 0,24 & $6 \times 10$ & 27,3 & 0,46 & $9 \times 14$ & 21,9 & 0,33 & $13 \times 18$ & 23,8 & 0,40 \\
\hline $1 \times 9$ & 20,1 & 0,36 & $3 \times 16$ & 24,7 & 0,26 & $6 \times 11$ & 44,8 & 0,60 & $9 \times 15$ & 20,1 & 0,33 & $13 \times 19$ & 25,2 & 0,43 \\
\hline $1 \times 10$ & 30,4 & 0,50 & $3 \times 17$ & 30,6 & 0,42 & $6 \times 12$ & 6,1 & 0,12 & $9 \times 16$ & 8,5 & 0,16 & $13 \times 20$ & 23,2 & 0,38 \\
\hline $1 \times 11$ & 60,0 & 0,74 & $3 \times 18$ & 14,4 & 0,16 & $6 \times 13$ & 10,5 & 0,19 & $9 \times 17$ & 30,7 & 0,51 & $13 \times 21$ & 26,6 & 0,39 \\
\hline $1 \times 12$ & 20,4 & 0,36 & $3 \times 19$ & 46,6 & 0,49 & $6 \times 14$ & 29,3 & 0,46 & $9 \times 18$ & 22,6 & 0,39 & $13 \times 22$ & 31,0 & 0,48 \\
\hline $1 \times 13$ & 14,1 & 0,26 & $3 \times 20$ & 28,9 & 0,41 & $6 \times 15$ & 16,3 & 0,25 & $9 \times 19$ & 38,4 & 0,60 & $14 \times 15$ & 44,5 & 0,55 \\
\hline $1 \times 14$ & 32,4 & 0,49 & $3 \times 21$ & 24,1 & 0,38 & $6 \times 16$ & 7,9 & 0,15 & $9 \times 20$ & 31,6 & 0,52 & $14 \times 16$ & 53,5 & 0,73 \\
\hline $1 \times 15$ & 21,7 & 0,35 & $3 \times 22$ & 19,3 & 0,29 & $6 \times 17$ & 21,4 & 0,38 & $9 \times 21$ & 42,3 & 0,62 & $14 \times 17$ & 58,0 & 0,81 \\
\hline $1 \times 16$ & 17,1 & 0,31 & $4 \times 5$ & 45,2 & 0,67 & $6 \times 18$ & 12,6 & 0,23 & $9 \times 22$ & 36,0 & 0,56 & $14 \times 18$ & 46,8 & 0,70 \\
\hline $1 \times 17$ & 25,9 & 0,44 & $4 \times 6$ & 34,4 & 0,56 & $6 \times 19$ & 22,4 & 0,37 & $10 \times 11$ & 38,9 & 0,56 & $14 \times 19$ & 52,4 & 0,66 \\
\hline $1 \times 18$ & 18,3 & 0,32 & $4 \times 7$ & 45,0 & 0,68 & $6 \times 20$ & 16,2 & 0,29 & $10 \times 12$ & 26,6 & 0,6 & $14 \times 20$ & 27,3 & 0,46 \\
\hline $1 \times 19$ & 23,7 & 0,40 & $4 \times 8$ & 41,8 & 0,59 & $6 \times 21$ & 18,1 & 0,29 & $10 \times 13$ & 18,5 & 0,31 & $14 \times 21$ & 35,1 & 0,58 \\
\hline $1 \times 20$ & 16,8 & 0,29 & $4 \times 9$ & 11,5 & 0,21 & $6 \times 22$ & 22,4 & 0,38 & $10 \times 14$ & 28,1 & 0,47 & $14 \times 22$ & 39,0 & 0,62 \\
\hline $1 \times 21$ & 17,1 & 0,27 & $4 \times 10$ & 24,8 & 0,40 & $7 \times 8$ & 61,4 & 0,83 & $10 \times 15$ & 38,6 & 0,54 & $15 \times 16$ & 40,9 & 0,63 \\
\hline $1 \times 22$ & 17,0 & 0,28 & $4 \times 11$ & 46,8 & 0,56 & $7 \times 9$ & 38,7 & 0,62 & $10 \times 16$ & 19,0 & 0,32 & $15 \times 17$ & 39,0 & 0,55 \\
\hline $2 \times 3$ & 66,2 & 0,84 & $4 \times 12$ & 21,4 & 0,36 & $7 \times 10$ & 41,4 & 0,65 & $10 \times 17$ & 34,7 & 0,57 & $15 \times 18$ & 38,4 & 0,55 \\
\hline $2 \times 4$ & 49,2 & 0,68 & $4 \times 13$ & 5,4 & 0,10 & $7 \times 11$ & 52,5 & 0,69 & $10 \times 18$ & 36,2 & 0,59 & $15 \times 19$ & 34,8 & 0,57 \\
\hline $2 \times 5$ & 37,1 & 0,59 & $4 \times 14$ & 27,7 & 0,38 & $7 \times 12$ & 21,5 & 0,38 & $10 \times 19$ & 42,6 & 0,61 & $15 \times 20$ & 34,2 & 0,48 \\
\hline $2 \times 6$ & 43,4 & 0,66 & $4 \times 15$ & 17,4 & 0,31 & $7 \times 13$ & 20,9 & 0,37 & $10 \times 20$ & 45,4 & 0,70 & $15 \times 21$ & 35,5 & 0,44 \\
\hline $2 \times 7$ & 57,0 & 0,80 & $4 \times 16$ & 22,8 & 0,40 & $7 \times 14$ & 31,1 & 0,49 & $10 \times 21$ & 48,0 & 072 & $15 \times 22$ & 36,8 & 0,49 \\
\hline $2 \times 8$ & 53,7 & 0,79 & $4 \times 17$ & 22,1 & 0,36 & $7 \times 15$ & 27,1 & 0,41 & $10 \times 22$ & 49,4 & 0,74 & $16 \times 17$ & 40,2 & 0,63 \\
\hline $2 \times 9$ & 30,2 & 0,48 & $4 \times 18$ & 10,9 & 0,17 & $7 \times 16$ & 18,0 & 0,32 & $11 \times 12$ & 24,1 & 0,33 & $16 \times 18$ & 37,1 & 0,59 \\
\hline $2 \times 10$ & 38,9 & 0,62 & $4 \times 19$ & 21,8 & 0,39 & $7 \times 17$ & 34,9 & 0,57 & $11 \times 13$ & 25,8 & 0,30 & $16 \times 19$ & 35,2 & 0,57 \\
\hline $2 \times 11$ & 62,8 & 0,83 & $4 \times 20$ & 19,3 & 0,31 & $7 \times 18$ & 21,1 & 0,38 & $11 \times 14$ & 22,9 & 0,39 & $16 \times 20$ & 28,3 & 0,47 \\
\hline $2 \times 12$ & 20,7 & 0,35 & $4 \times 21$ & 14,1 & 0,17 & $7 \times 19$ & 33,7 & 0,52 & $11 \times 15$ & 43,3 & 0,46 & $16 \times 21$ & 27,7 & 0,42 \\
\hline $2 \times 13$ & 24,7 & 0,38 & $4 \times 22$ & 10,3 & 0,13 & $7 \times 20$ & 23,5 & 0,41 & $11 \times 16$ & 25,1 & 0,30 & $16 \times 22$ & 25,7 & 0,41 \\
\hline $2 \times 14$ & 24,6 & 0,43 & $5 \times 6$ & 35,2 & 0,58 & $7 \times 21$ & 34,3 & 0,54 & $11 \times 17$ & 28,8 & 0,43 & $17 \times 18$ & 38,2 & 0,62 \\
\hline $2 \times 15$ & 35,5 & 0,46 & $5 \times 7$ & 34,0 & 0,56 & $7 \times 22$ & 27,4 & 0,46 & $11 \times 18$ & 21,9 & 0,32 & $17 \times 19$ & 56,4 & 0,76 \\
\hline $2 \times 16$ & 22,9 & 0,36 & $5 \times 8$ & 34,4 & 0,56 & $8 \times 9$ & 48,9 & 0,70 & $11 \times 19$ & 42,7 & 0,47 & $17 \times 20$ & 22,3 & 0,40 \\
\hline $2 \times 17$ & 27,0 & 0,46 & $5 \times 9$ & 9,2 & 0,17 & $8 \times 10$ & 46,7 & 0,71 & $11 \times 20$ & 22,2 & 0,34 & $17 \times 21$ & 44,5 & 0,68 \\
\hline $2 \times 18$ & 14,6 & 0,26 & $5 \times 10$ & 27,9 & 0,48 & $8 \times 11$ & 49,5 & 0,72 & $11 \times 21$ & 24,4 & 0,41 & $17 \times 22$ & 38,6 & 0,62 \\
\hline $2 \times 19$ & 35,3 & 0,48 & $5 \times 11$ & 48,9 & 0,67 & $8 \times 12$ & 37,8 & 0,59 & $11 \times 22$ & 20,1 & 0,32 & $18 \times 19$ & 37,7 & 0,56 \\
\hline $2 \times 20$ & 31,2 & 0,52 & $5 \times 12$ & 17,9 & 0,33 & $8 \times 13$ & 30,9 & 0,47 & $12 \times 13$ & 37,5 & 0,60 & $18 \times 20$ & 43,5 & 0,68 \\
\hline $2 \times 21$ & 27,4 & 0,47 & $5 \times 13$ & 6,8 & 0,12 & $8 \times 14$ & 29,2 & 0,50 & $12 \times 14$ & 40,5 & 0,61 & $18 \times 21$ & 41,3 & 0,64 \\
\hline $2 \times 22$ & 18,9 & 0,34 & $5 \times 14$ & 11,7 & 0,20 & $8 \times 15$ & 42,0 & 0,54 & $12 \times 15$ & 55,9 & 0,76 & $18 \times 22$ & 48,9 & 0,73 \\
\hline $3 \times 4$ & 59,5 & 0,67 & $5 \times 15$ & 22,3 & 0,33 & $8 \times 16$ & 23,9 & 0,37 & $12 \times 16$ & 48,1 & 0,73 & $19 \times 20$ & 35,9 & 0,52 \\
\hline $3 \times 5$ & 40,1 & 0,54 & $5 \times 16$ & 11,8 & 0,21 & $8 \times 17$ & 35,9 & 0,58 & $12 \times 17$ & 32,9 & 0,55 & $19 \times 21$ & 51,6 & 0,66 \\
\hline $3 \times 6$ & 47,6 & 0,60 & $5 \times 17$ & 14,2 & 0,26 & $8 \times 18$ & 23,2 & 0,40 & $12 \times 18$ & 32,3 & 0,54 & $19 \times 22$ & 41,1 & 0,57 \\
\hline $3 \times 7$ & 68,1 & 0,81 & $5 \times 18$ & 13,3 & 0,25 & $8 \times 19$ & 54,1 & 0,70 & $12 \times 19$ & 38,5 & 0,59 & $20 \times 21$ & 40,1 & 0,63 \\
\hline $3 \times 8$ & 57,4 & 0,77 & $5 \times 19$ & 18,9 & 0,29 & $8 \times 20$ & 28,1 & 0,48 & $12 \times 20$ & 28,0 & 0,48 & $20 \times 22$ & 36,6 & 0,60 \\
\hline & & & & & & & & & & & & $21 \times 22$ & 59,2 & 0,83 \\
\hline
\end{tabular}


apresentaram interação GxA com predominância de parte simples (PS\%> 50) e correlações acima de 0,50. No método tradicional (Tabela 4), pôde-se verificar que os grupos foram formados por ambientes onde a porção simples foi mais pronunciada, ou seja, as combinações entre os ambientes dentro de um mesmo grupo apresentaram PS\% $>50$ e r $>0,5$, com exceção do grupo E (ambiente 13 $\mathrm{x}$ ambiente 15, 47,8\% de PS), porém com $\mathrm{r}=0,71$.

Enquanto métodos fundamentados em regressão bissegmentada permitem a formação de dois subgrupos de ambientes, favorável ou desfavorável, a análise de fatores permite a formação de número maior de subgrupos, com ambientes altamente correlacionados dentro de cada grupo. Na técnica proposta por Murakami \& Cruz (2004), os três autovalores acima de 1 absorveram 73,3\% da variação total (Tabela 6). Optou-se por utilizar mais dois autovalores que, então, passaram a absorver $81,8 \%$ do total da variação. Foi fixado o número final de cinco fatores para serem utilizados nos agrupamentos. As comunalidades apresentaram valores acima de 0,70 , o que indica alta eficiência da representação das variáveis por uma parte comum. Segundo Souza, citado por Cruz \& Carneiro (2003), valores de comunalidades superiores a 0,64 têm sido aceitos como razoáveis, pois equivalem a uma correlação próxima de 0,80 entre a variável padronizada $\left(\mathrm{x}_{\mathbf{j}}\right) \mathrm{e}$ a parte comum que explica esta variável $\left(\mathrm{z}_{\mathrm{j}}\right)$.
O fator 1 permitiu o agrupamento dos ambientes 10 , $18,20,21$ e 22 , que obtiveram cargas fatoriais acima de 0,70 . Foram agrupadas duas localidades iguais em um mesmo fator (Ponta Grossa - 2003/2004 e 2004/2005), o que leva a inferir que os genótipos tiveram comportamentos similares nos dois ambientes. A resposta para tal fato pode ser fundamentada na distribuição regular de chuvas nessa localidade, nos dois anos agrícolas, nas baixas oscilações na temperatura média nos períodos e no adequado manejo fitotécnico nos ensaios. $\mathrm{O}$ fator 2 gerou um subgrupo que continha os ambientes 1, 2, 3, 4, 5, 6, 7 e 11 . O fator 3 agrupou os ambientes $12,13,15$ e 16 . O fator 4 gerou um subgrupo que continha somente o ambiente 9 , assim como o fator 5 com o ambiente 14 . Os ambientes 8,17 e 19 não foram agrupados em nenhum dos cinco fatores, por não atingirem cargas fatoriais acima de 0,70 .

Foi possível verificar que tanto ambientes favoráveis quanto desfavoráveis, na análise de fatores, pertenceram a grupos iguais de similaridade. No caso do melhoramento genético, esse tipo de estratificação, que se baseia em coeficientes de correlação, permite minimizar os efeitos da interação GxA e, no caso de sua existência, permite que a parte atuante seja de natureza simples.

Verificou-se que as localidades de Londrina e Cambará, quando analisadas separadamente por safras (2004/2005 e 2003/2004), permaneceram agrupadas em um mesmo fator ( 2 e 3 , respectivamente), o que indica

Tabela 6. Estratificação ambiental por meio da análise de fatores, com 27 genótipos de milho avaliados em 22 ambientes no Estado do Paraná, nas safras 2003/2004 e 2004/2005.

\begin{tabular}{|c|c|c|c|c|c|c|c|c|c|}
\hline \multirow[t]{2}{*}{ Autovalor } & \multirow{2}{*}{$\begin{array}{c}\text { Porcentagem } \\
\text { acumulada }\end{array}$} & \multirow[t]{2}{*}{ Ambientes } & \multirow[t]{2}{*}{ Ano } & \multicolumn{5}{|c|}{ Cargas fatoriais após rotação } & \multirow[t]{2}{*}{ Comunalidades } \\
\hline & & & & Fator 1 & Fator 2 & Fator 3 & Fator 4 & Fator 5 & \\
\hline 11,29 & 51,3 & 1. Londrina & $2004 / 2005$ & 0,068 & $-0,902$ & 0,131 & 0,100 & $-0,216$ & 0,89 \\
\hline 3,19 & 65,8 & 2. Cambará & $2004 / 2005$ & 0,209 & $-0,834$ & 0,210 & 0,277 & $-0,054$ & 0,86 \\
\hline 1,64 & 73,3 & 3. Campo Mourão & $2004 / 2005$ & 0,096 & $-0,829$ & 0,073 & 0,347 & $-0,108$ & 0,83 \\
\hline 0,98 & 77,7 & 4. Goioerê & $2004 / 2005$ & 0,018 & $-0,832$ & 0,196 & $-0,121$ & $-0,126$ & 0,76 \\
\hline 0,90 & 81,8 & 5. Palotina & $2004 / 2005$ & 0,199 & $-0,802$ & 0,157 & $-0,212$ & 0,132 & 0,77 \\
\hline 0,72 & 85,1 & 6. Cascavel & $2004 / 2005$ & 0,197 & $-0,739$ & $-0,117$ & $-0,008$ & $-0,328$ & 0,71 \\
\hline 0,58 & 87,7 & 7. Pato Branco & $2004 / 2005$ & 0,241 & $-0,745$ & 0,167 & 0,408 & $-0,178$ & 0,84 \\
\hline 0,47 & 89,9 & 8. Francisco Beltrão & $2004 / 2005$ & 0,334 & $-0,674$ & 0,308 & 0,475 & $-0,119$ & 0,90 \\
\hline 0,44 & 91,9 & 9. Guarapuava & $2004 / 2005$ & 0,479 & $-0,232$ & 0,115 & 0,726 & $-0,059$ & 0,83 \\
\hline 0,33 & 93,4 & 10. Ponta Grossa & $2004 / 2005$ & 0,757 & $-0,445$ & 0,176 & 0,258 & $-0,029$ & 0,87 \\
\hline 0,32 & 94,8 & 11. Wenceslau Bráz & $2004 / 2005$ & 0,196 & $-0,792$ & 0,193 & 0,147 & $-0,054$ & 0,73 \\
\hline 0,28 & 96,1 & 12. Londrina & $2003 / 2004$ & 0,249 & $-0,203$ & 0,854 & 0,043 & $-0,115$ & 0,85 \\
\hline 0,20 & 97,0 & 13. Cambará & $2003 / 2004$ & 0,103 & $-0,065$ & 0,724 & 0,394 & $-0,227$ & 0,75 \\
\hline 0,18 & 97,8 & 14. Campo Mourão & $2003 / 2004$ & 0,330 & $-0,255$ & 0,425 & 0,007 & $-0,754$ & 0,92 \\
\hline 0,13 & 98,4 & 15. Goioerê & $2003 / 2004$ & 0,318 & $-0,222$ & 0,809 & 0,096 & $-0,064$ & 0,82 \\
\hline 0,11 & 98,9 & 16. Palotina & $2003 / 2004$ & 0,218 & $-0,162$ & 0,721 & $-0,159$ & $-0,449$ & 0,82 \\
\hline 0,09 & 99,3 & 17. Cascavel & $2003 / 2004$ & 0,316 & $-0,252$ & 0,401 & 0,291 & $-0,675$ & 0,86 \\
\hline 0,06 & 99,6 & 18. Pato Branco & $2003 / 2004$ & 0,747 & $-0,083$ & 0,364 & $-0,121$ & $-0,374$ & 0,85 \\
\hline 0,04 & 99,8 & 19. Francisco Beltrão & $2003 / 2004$ & 0,413 & $-0,296$ & 0,394 & 0,330 & $-0,421$ & 0,70 \\
\hline 0,03 & 99,9 & 20. Guarapuava & $2003 / 2004$ & 0,776 & $-0,228$ & 0,315 & 0,066 & 0,027 & 0,76 \\
\hline 0,01 & 100,0 & 21. Ponta Grossa & $2003 / 2004$ & 0,724 & $-0,141$ & 0,122 & 0,396 & $-0,370$ & 0,85 \\
\hline 0,00 & 100,0 & 22. Wenceslau Bráz & $2003 / 2004$ & 0,774 & $-0,109$ & 0,193 & 0,244 & $-0,350$ & 0,83 \\
\hline
\end{tabular}


haver alta correlação entre as duas localidades dentro de um mesmo ano agrícola, e baixa correlação quando estas localidades são analisadas entre os anos agrícolas.

Londrina e Cambará, durante a safra 2004/2005, apresentaram alto porcentual de parte simples $(62,9 \%)$, ao passo que, na safra 2003/2004, a maior porção atuante foi a de natureza complexa (PS\% $=37,5)$. As diferenças no ranqueamento dos genótipos, refletidas neste último porcentual, podem estar ligadas à alta temperatura que ocorreu em Cambará durante aquele período. Londrina, apesar de ter sido atingida por uma estiagem durante aquela safra, apresentou chuvas na época do florescimento que contribuíram para que se mantivesse a alta produtividade. Goioerê e Palotina, apesar de terem sido agrupadas por safra em fatores iguais, apresentaram, nos dois anos agrícolas, predominância de parte complexa na interação GxA. Londrina e Goioerê, dentro de uma mesma safra, foram agrupadas em um mesmo fator, ao passo que entre as safras, ficaram agrupadas em fatores separados. Ainda, dentro de cada safra, apresentaram altos valores para PS\%, assim como para $r$, o que indica que essas duas localidades poderiam ser reduzidas a somente um local de ensaio.

Para as análises de dispersão gráfica, obtidas a partir dos escores fatoriais, optou-se por considerar os três primeiros fatores que agruparam 17 ambientes, de um total de 19 que apresentaram cargas fatoriais finais acima de 0,70 .

Os genótipos 1, 3, 4, 11, 12 e 20 apresentaram adaptação específica aos ambientes agrupados no fator 1 (10, $18,20,21$ e 22), pelo fato de estarem concentrados no quadrante IV das Figuras 1 e 2. Uma adaptação aos ambientes agrupados no fator 2 foi verificada para os genótipos 7, 8 e 25, uma vez que estes se concentraram nos quadrantes II, da Figura 1, e IV da Figura 3. Os genótipos 5, 10, 21, 23, 26 e 27 apresentaram adaptação aos ambientes contidos no fator 3 (posicionamento no quadrante II das Figuras 2 e 3). Foi constatado que os genótipos 2, 19 e 22 apresentaram adaptação aos ambientes agrupados pelos fatores 1 e 3 , por ficarem posicionados no quadrante IV da Figura 1, quadrante I da Figura 2 e quadrante II da Figura 3. O genótipo 6 apresentou adaptação tanto nos ambientes compreendidos no fator 2, quanto no fator 3 (quadrantes II das Figuras 1 e 2 e quadrante I da Figura 3). Os genótipos $9,13,14,15,17$ e 24 apresentaram ampla adaptação aos 17 ambientes, contidos nos três fatores considerados, tendo englobado $89,5 \%$ dos ambientes com cargas fatoriais acima de 0,70 . Os genótipos que permanece- ram posicionados no quadrante III, nas três plotagens gráficas, foram 16 e 18, passíveis de descarte na recomendação por apresentarem baixa adaptabilidade nos ambientes considerados.

Pelo método de regressão bissegmentada, segundo Cruz et al. (2004), o genótipo 13 seria recomendado para ambientes favoráveis em razão da alta produtividade, $\beta_{1}>1$ e $\beta_{1}+\beta_{2}>1$. No entanto, pela análise de fatores, constatou-se que esse genótipo apresentou adaptabilidade ampla nos 17 ambientes agrupados nos fatores 1 , 2 e 3 , tanto favoráveis quanto desfavoráveis. O genótipo 16 seria recomendado para ambientes desfavoráveis, uma vez que apresentou alta produtividade, $\beta_{1}<1$ e $\beta_{1}+\beta_{2}<1$. Pela análise de fatores, este mesmo genótipo passaria a ser descartado, pela baixa adaptabilidade nos grupos formados. Constatou-se que o mé-

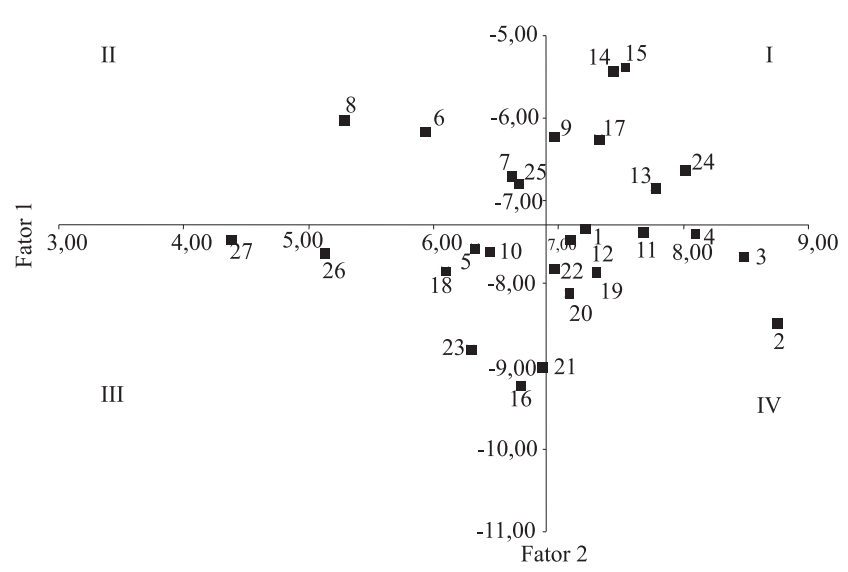

Figura 1. Análise gráfica da adaptabilidade de 27 genótipos de milho, a partir dos escores obtidos, tendo-se considerado 13 ambientes contidos nos fatores 1 e 2.

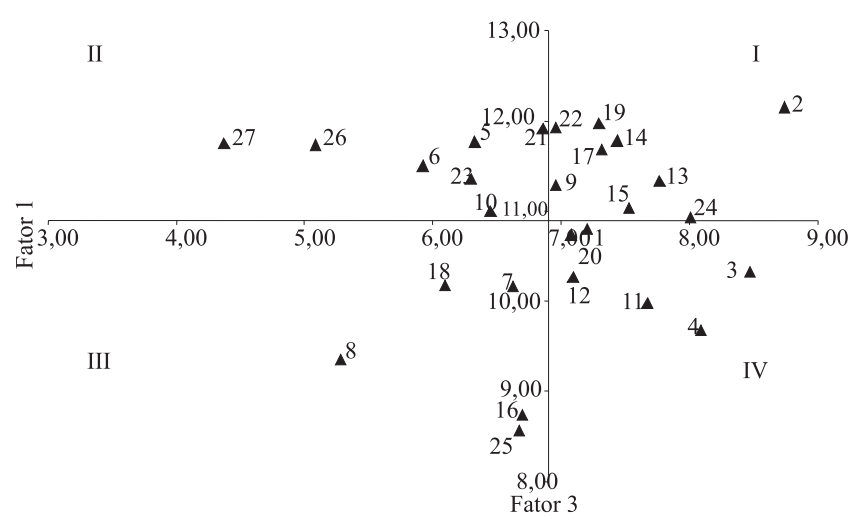

Figura 2. Análise gráfica da adaptabilidade de 27 genótipos de milho, a partir dos escores obtidos, tendo-se considerado 9 ambientes contidos nos fatores 1 e 3 . 


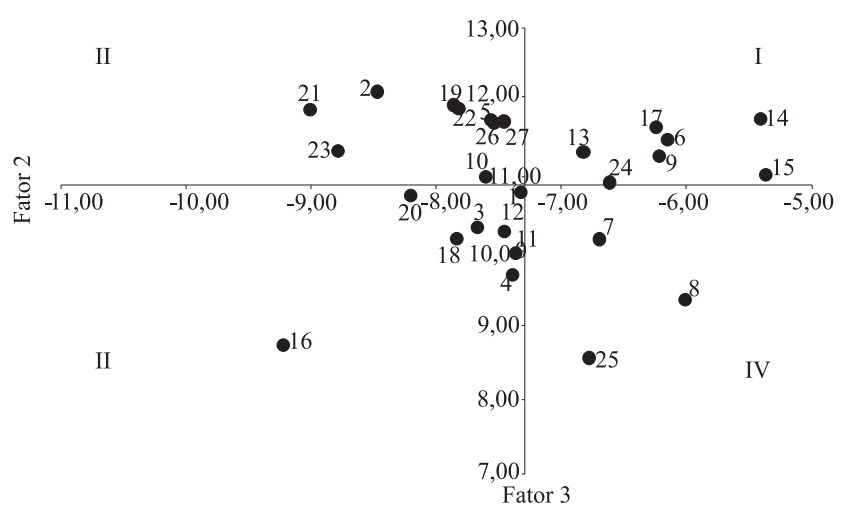

Figura 3. Análise gráfica da adaptabilidade de 27 genótipos de milho, a partir dos escores obtidos, tendo-se considerado 12 ambientes contidos nos fatores 2 e 3 .

todo de regressão bissegmentada, baseado em índices ambientais, apresentou inferências opostas, ou parcialmente opostas, quando comparadas às obtidas na análise de fatores, que tem sua fundamentação em coeficientes de correlação e na performance genotípica das cultivares.

\section{Conclusões}

1. A técnica baseada em análise de fatores, aliada ao método proposto por Cruz \& Castoldi se mostra mais eficiente no processo de estratificação ambiental, uma vez que permite agrupamentos entre ambientes altamente correlacionados, o que não acontece com o método tradicional de Lin.

2. Londrina e Goioerê podem ser reduzidas a somente um local de ensaio.

3. Por meio dos parâmetros de adaptabilidade, obtidos pela análise de regressão bissegmentada, não se constata o genótipo tido como ideal pela literatura, apesar do elevado potencial produtivo demonstrado pelas cultivares, e isto pode ser uma falha do método.

4. A adaptabilidade dos genótipos, analisada por meio de plotagens gráficas a partir dos escores fatoriais, apre- senta respostas diferenciadas, quando comparada ao método de regressão bissegmentada.

5. A análise de fatores é uma ferramenta eficiente nos processos de estratificação ambiental e nos estudos de adaptabilidade dos genótipos de milho.

\section{Referências}

BANZATTO, D.A.; KRONKA, S.N. Experimentação agrícola. Jaboticabal: Funep, 1995. 247p.

CRUZ, C.D. Genes v.2005.0.0: aplicativo computacional em genética e estatística. Viçosa: Universidade Federal de Viçosa, Departamento de Biologia Geral, 2005. Disponível em: < http://www.ufv.br/dbg/ genes/genes.htm >. Acesso em: jan. 2007.

CRUZ, C.D.; CARNEIRO, P.C.S. Modelos biométricos aplicados ao melhoramento genético. Viçosa: UFV, 2003. v.2. 585p.

CRUZ, C.D.; CASTOLDI, F. Decomposição da interação genótipo $\mathrm{x}$ ambientes em partes simples e complexa. Revista Ceres, v.38, p.422-430, 1991.

CRUZ, C.D.; REGAZZI, A.J.; CARNEIRO, P.C.S. Modelos biométricos aplicados ao melhoramento genético. Viçosa: UFV, 2004. v.1. 480p.

CRUZ, C.D.; TORRES, R.A.D.; VENCOVSKY, R. An alternative approach to the stability analysis proposed by Silva and Barreto. Revista Brasileira de Genética, v.12, p.567-580, 1989.

LIN, C.S. Grouping genotypes by a cluster method directly related to genotype-environment interaction mean-square. Theoretical and Applied Genetics, v.62, p.277-280, 1982.

MURAKAMI, D.M.; CRUZ, C.D. Proposal of methodologies for environment stratification and analysis of genotype adaptability. Crop Breeding and Applied Biotechnology, v.4, p.7-11, 2004.

OLIVEIRA, G.V. de; CARNEIRO, P.C. de S.; DIAS, L.A. dos S.; CARNEIRO, J.E. de S.; CRUZ, C.D. Factor analysis in the environment stratification for the evaluation of common bean cultivars. Crop Breeding and Applied Biotechnology, v.5, p.166173, 2005.

ROBERTSON, A. Experimental design on the measurement of heritabilities and genetic correlations: biometrical genetics. New York: Pergamon Press, 1959. 186p.

SAS INSTITUTE (Cary, Estados Unidos). SAS/STAT software: changes and enhancements through release 8.02. Cary, 1999. 3 CD-ROM.

Recebido em 2 de março de 2006 e aprovado em 6 de dezembro de 2006 